\title{
EXPERIMENTAL INVESTIGATION OF TRANSITION TO TURBULENCE AS AFFECTED BY PASSING WAKES
}

\author{
Richard W. Kaszeta and Terrence W. Simon \\ Heat Transfer Laboratory \\ University of Minnesota \\ Minneapolis, MN 55455, U.S.A. \\ David E. Ashpis \\ National Aeronautics and Space Administration \\ John H. Glenn Research Center at Lewis Field \\ Cleveland, $\mathrm{OH} 44135-3191$
}

\section{ABSTRACT}

This paper presents experimental results from a study of the effects of periodically passing wakes upon laminar-to-turbulent transition and separation in a low-pressure turbine passage. The test section geometry is designed to simulate unsteady wakes in turbine engines for studying their effects on boundary layers and separated flow regions over the suction surface by using a single suction surface and a single pressure surface to simulate a single turbine blade passage. Single-wire, thermal anemometry techniques are used to measure time-resolved and phaseaveraged, wall-normal profiles of velocity, turbulence intensity and intermittency at multiple streamwise locations over the turbine airfoil suction surface. These data are compared to steady-state wake-free data collected in the same geometry to identify the effects of wakes upon laminar-to-turbulent transition. Results are presented for flows with a Reynolds number based on suction surface length and stage exit velocity of 50,000 and an approach flow turbulence intensity of $2.5 \%$. While both existing design and experimental data are primarily concerned with higher Reynolds number flows $(R e>100,000)$, recent advances in gas turbine engines, and the accompanying increase in laminar and transitional flow effects, have made low-Re research increasingly important.

From the presented data, the effects of passing wakes on transition and separation in the boundary layer, due to both increased turbulence levels and varying streamwise pressure gradients are presented. The results show how the wakes affect transition. The wakes affect the flow by virtue of their difference in turbulence levels and scales from those of the free-stream and by virtue of their ensemble-averaged velocity deficits, relative to the free-stream velocity, and the concomitant changes in angle of attack and temporal pressure gradients. The relationships between the velocity oscillations in the freestream and the unsteady velocity profile shapes in the near-wall flow are described. In this discussion is support for the theory that bypass transition is a response of the near-wall vis- cous layer to pressure fluctuations imposed upon it from the free-stream flow. Recent transition models are based on that premise. The data also show a significant lag between when the wake is present over the surface and when transition begins.

\section{NOMENCLATURE}

$\begin{array}{ll}C_{p} & \text { Pressure coefficient } \\ f & \text { Frequency }\end{array}$

FSTI Freestream turbulence intensity

$L \quad$ True chord length

$L_{u} \quad$ Energy length scale

$L_{x} \quad$ Axial chord length

$L_{\mathrm{s} s} \quad$ Suction surface chord length

$P \quad$ Blade pitch

$\operatorname{Re}_{\theta, r} \quad$ Reynolds number based on momentum thickness at the location of onset of transition

$R e_{L_{s s}} \quad$ Reynolds number based on suction surface length, $L_{s s}$, and passage exit velocity

$S \quad$ Wake Strouhal number, $f L_{x} / u_{x}$

$s \quad$ Distance along the blade's suction surface

$T \quad$ Wake passing period

$i$ Time

TI Turbulence intensity

u Streamwise component of velocity

$u_{r} \quad$ Rod velocity

$u_{x} \quad$ Axial component of inlet velocity

$x \quad$ Axial distance from blade leading edge

$y \quad$ Normal distance from the suction surface

Greek:

$\beta_{1} \quad$ Blade inlet angle

This is a preprint or reprint of a paper intended for presentation at a conference. Because changes may be made before formal publication, this is made available with the understanding that it will not be cited or reproduced without the permission of the author. 


$\begin{array}{ll}\beta_{2} & \text { Blade outlet angle } \\ \varepsilon & \text { Dissipation of turbulent kinetic energy } \\ \gamma & \text { Turbulence intermittency } \\ \lambda & \text { Taylor microscale } \\ \Lambda & \text { Integral length scale of turbulence }\end{array}$

Sub/Superscripts:

- Phase-average

\section{INTRODUCTION}

Low Pressure Turbines (LPT) are commonly used in the aerospace industry, primarily to provide input shaft power for fan and compressor components of the turbine engines. Turbine design engineers seek to develop engines of increased efficiency and decreased wcight, while reducing cost. The LPT has been shown to be a component worthy of attention in this endeavor. Key to such improvement in the LPT is a better understanding of low-Reynolds-number flow transition and separation.

Transition to turbulence has been studied for many years. However, transition in LP turbine engines, with elevated disturbance levels and periodic unsteadiness, has been less well documented, until recently. High levels of freestream turbulence cause earlier transition than with lower turbulence levels and such transition can prevent separation in the adverse pressure gradient region on the trailing portion of the suction surface of a turbine airfoil. Thus, blades in such an environment may be designed for higher loading if the effects of bypass transition were properly included in the design. Exploitation of this concept is just beginning. In a seminal paper on this topic, Mayle [1] observed in 1991 that the majority of the experimental work which is focused upon laminarto-turbulent transition has been conducted under lower turbulence and steady flow conditions. However, the actual flow present in turbine engines has turbulence levels of 2-10\%, with significant unsteadiness due to wakes. Since 1991, considerable progress on the topic has ensued, as will be discussed. Mayle further suggested that investigations should be conducted to document the effects of wakes on transition over turbine airfoil surfaces. This has been addressed in recent years. A recent review of research on transition in LP turbines is presented by Simon and Kaszeta [2]. Recent progress in understanding boundary layer transition under high freestream turbulence is presented in Jacobs and Durbin [3].

\section{The Present Study}

While some experimental data which document the flow field and transition in turbomachinery flows exists, much of the research has been conducted under steady-state conditions. Of the unsteady-flow experimental studies, the majority presented only surface measurements, such as surface pseudo-shear stress through the use of hot-film sensors, or were conducted in more simplified geometries. Few in-flow measurements of turbine passages have been presented. The most recent study showing in-flow measurements was a study by Wolff et al. [4], in which velocity profiles and surface-mounted hot-film pseudo-shear-stress distributions near the trailing edge of an LP turbine blade in a turbine cascade were presented. Some profile measurements were given in Halstead et al. [5], but focus was on attached-flow transition. Similarly, boundary layer profiles over a curved plate disturbed by wakes were presented in Schobeiri et al. [6]. The present study addresses a need for detailed in-flow data by using hot-wire anemometry to collect wallnormal, time-resolved records of velocity, turbulence intensity, and interinittency.

This study utilizes a modified version of the turbine blade passage simulator used in Qiu and Simon [7], Qiu [8], and Simon et al. [9] with a wake generator added to introduce periodic wakes into the flow upstream of the turbine blade leading edge. Ensemble-averaged, wall-normal profiles of velocity, turbulence intensity and turbulence intermittency were measured over the turbine passage suction surface. By comparing these results to the Qiu study, the effects of wakes can be isolated. Also, the experimental geometry and the results are amenable to comparison with wake-disturbed, LP turbine computational works, such as those of Dorney et al. [10] and Wu and Durbin [11]. The results presented here will be used as an experimental database for model development and CFD validation, similar to the studies done by Suzen and Huang [12] for the no-wake results of Qiu and Simon [7].

\section{EXPERIMENTAL CONFIGURATION}

The experimental facility (Figs. 1 and 2 ) consists of a low-speed wind tunnel, a wake generator and a turbine blade passage simulator. The wake generator was designed by Yuan [13] to simulate wakes emerging from upstream turbine stages in a low pressure turbine. It consists of a moving sled assembly which contains a series of $0.635 \mathrm{~cm}$ $(0.25 \mathrm{in})$ stainless steel rods which simulate vane wakes, spaced at $80 \%$ of the blade chord length (the same spacing as the blade surfaces). The rods are located 12 rod diameters upstream from the leading edges. Note that this facility only simulates a turbine cascade, using a single pressure surface and a single suction surface to create a single turbine passage.

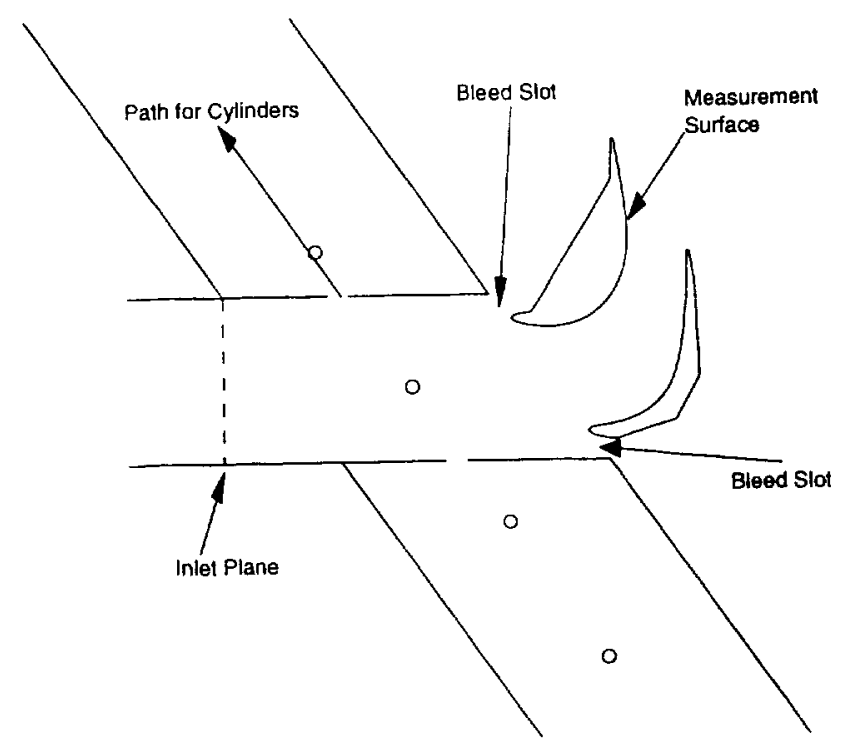

Figure 1. Cross-sectional view of the experimental facility.

\section{Instrumentation}

A TSI model IFA-100 hot-wire anemometer bridge was used for velocity measurements. The anemometer was calibrated against a Pitot tube under low-turbulence conditions using the same wind tunnel and 


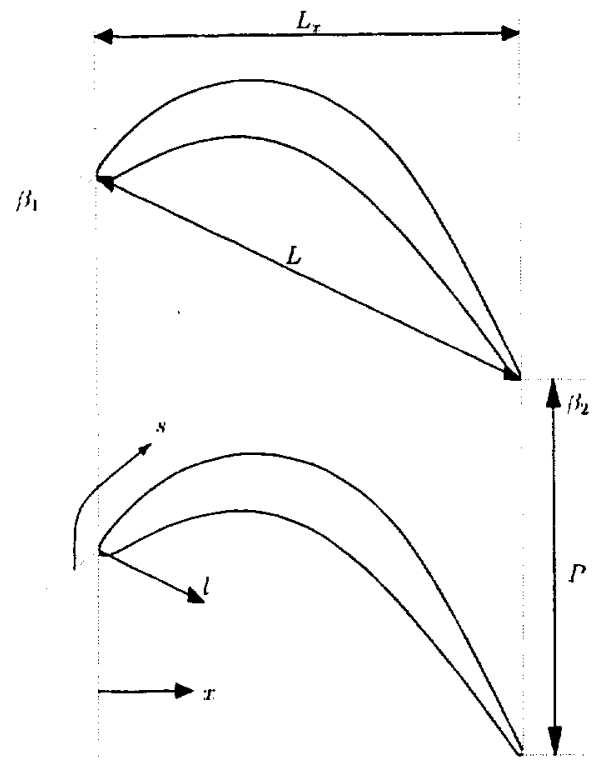

Chord length, $L$ :

$114 \mathrm{~mm}$

Axial chord length, $L_{x}$ :

$103.57 \mathrm{~mm}$

0.906

Axial chord to true chord ratio, $L_{x} / L$ :

0.8

Pitch to chord ratio, $P / L$ :

$35^{\circ}$

Blade inlet angle, $\beta_{1}$ :

$-60^{\circ}$

Blade outlet angle, $\beta_{2}$

$\sim 0.70$

Relocity to axial flow velocity ratio, $u_{r} / u_{x}$

50,000

22,875

$R e$ based on $L$ and approach velocity:

$2.5 \%$

Nominal inlet FSTI:

0.792

Wake Strouhal Number, $S$ :

$4.44 \mathrm{~cm}$

Inlet Turbulence Length Scale, $\Lambda_{u x}$;

$1.21 \mathrm{~cm}$

Inlet Turbulence Length Scale, $\Lambda_{v, x}$ :

$0.99 \mathrm{~cm}$

Inlet Turbulence Length Scale, $\Lambda_{w, x}$

$1.25 \mathrm{~cm}$

Taylor Microscale, $\lambda$ :

Turbulent Dissipation, $\varepsilon$ :

$5.05 \mathrm{~mm}$

$0.049 \mathrm{~m}^{2} / \mathrm{s}^{3}$

Figure 2. Important Flow and Geometry Characteristics

operating conditions as the experiment. The anemometer's output was low-pass filtered at $20 \mathrm{kHz}$ using the bridge's built-in filters. The anemometer's output was sampled at $100 \mathrm{kHz}$ using an IOtech ADC488/8SA analog-to-digital converter. With an approach flow of approximately $3 \mathrm{~m} / \mathrm{s}$, spectral measurements indicated that these filtering and sampling rates were sufficiently high to resolve the turbulent frequencies present in the flow.

\section{Experimental Procedure}

Wall-normal profiles were collected at 12 streamwise locations along the suction surface and at 30 different wall-normal distances ranging from $y=0.1 \mathrm{~mm}$ to $y=16.5 \mathrm{~mm}$, unevenly spaced ranging from $\Delta y=0.1 \mathrm{~mm}$ near the wall to $\Delta y=1 \mathrm{~mm}$ approaching the freestream. The near-wall velocity results were corrected for conduction errors using the technique describe by Wills [14]. The data presented here represent only a small subset of the full data set. Although profiles were taken at each of these 12 stations, only those at $47 \%$ and $68 \%$ of the suction surface length downstream of the nominal stagnation point are presented. These two locations were chosen because they are good representations of the general flow character both before and after separation occurs (at approximately $55 \%$ of the suction surface length between wakes, and at about $70 \%$ within the wakes). Additionally, by examining the data from each profile at a fixed $y$-value, we can present the data as series of $s-t$ planes, showing the development of the flow as it travels along the blade surface.

The wake generator is run to create a series of wakes. Each series of wakes is decomposed into individual wakes from signals provided from a photogate (a high-speed infrared diode/transistor combination that signals when each rod enters the channel) mounted on the wake generalor which signals when each rod has entered the flow upstream of the turbine passage. Each wake is then further decomposed into 45 segments, each representing $2.22 \%$ of the wake's signal (the results are presented in terms of non-dimensional time, $t / T$, with $T$ being the period of wake passage). The segments from each of 140 wakes are then ensemble-averaged to obtain the the phase-averaged velocity, $\bar{u}$, and the rms velocity fluctuation, $\widetilde{u_{r m 2 s}}$. Additionally, the raw velocity signals are processed using the Turbulent Event Recognition Algorithm (TERA) of Falco and Gendrich [15], as modified by Walker and Solomon [16], 10 obtain turbulence intermittencies, and the phase average intermittency, $\bar{\gamma}$ is calculated from these values. These measurements are taken at 30 $y$-positions and at $12 s$-positions.

\section{Experimental Uncertainty}

Using standard thermal anemometry error estimation techniques, the level of uncertainty (with $95 \%$ confidence) of the velocity measurements was determined to be $\delta u / u \approx 4.7 \%$, quite acceptable for measurement of boundary layer profiles. This analysis applies to attached boundary layer flow measurements with local turbulence intensity values of less than $25 \%$. In some cases, one or both of these requirements were violated and such data are only approximate. These cases are discussed in detail in Kaszeta [17].

\section{APPROACH FLOW CHARACTERIZATION}

The ensemble-average velocity, $\tilde{u}(t)$, and turbulence intensity, $\tilde{T}(t)$, of the incoming wakes are shown in Fig. 3. These data, collected at the entrance of the test channel, midway between the leading edges, represent the ensemble averages of 600 wakes ( 4 wakes per sled passing, 150 sled passings). Examining Fig. 3, we see that the minimum velocity of the wake is approximately $87.5 \%$ of the average value. This profile matches the wake velocity characteristic recommended by Halstead [18] in which il rotating airfoil stage (simulating a rotating turbine stage) was used to create wake profiles. Note, however, that the wakes are quite broad and that the edges of the wakes merge-there is no quiescent period between wakes (a similar data case using an increased rod-spacing to produce lower-frequency wakes in in progress). Also, from these results it was found that the ensemble averages of the wakes converged for ensembles of 75 or more wakes, so a final ensemble size of 140 wakes was selected in subsequent experiments.

Examining the turbulence intensity profile, however, we see that it 


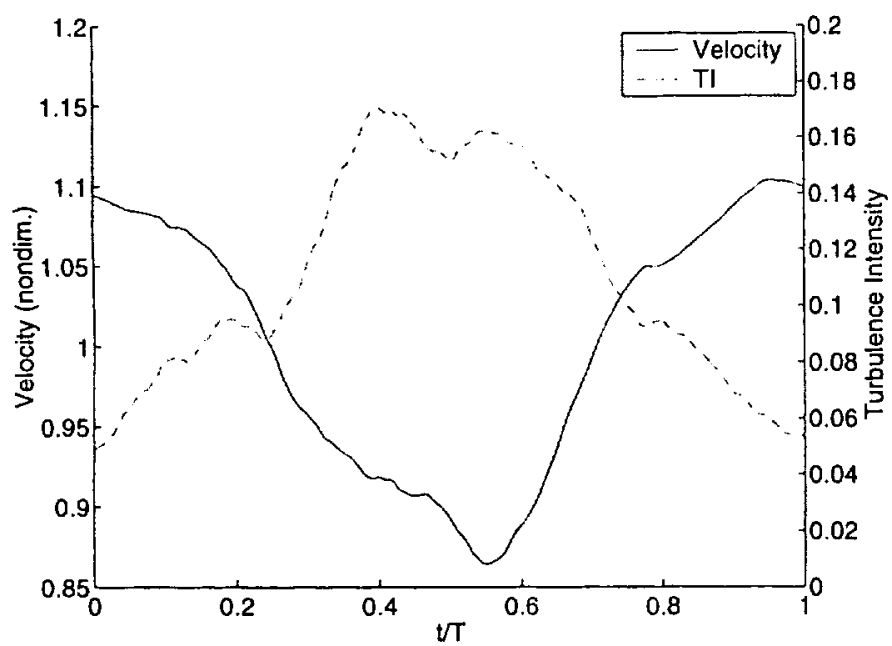

Figure 3. Ensemble average velocity and $T I$ of 600 wakes, taken at the midpoint between the leading cdges of the pressure and suction surfaces

peaks at $17.5 \%$, more than twice that reported by Halstead. This may be consistent with Halstead's assertion that rods seem to produce more turbulence than airfoils of the same loss coefficient. It should be noted, however, that the flows over the airfoils of the Halstead study were not separated and a highly loaded airfoil, such as the one describe here, would be inclined to separate at the lower Reynolds numbers typical of the present case and, thus, the wakes of the present case should contain higher levels and larger scales of turbulence. At this streamwise location, $T I$ is about $5 \%$ between wakes though the grid-generated turbulence of the flow approaching the wake generator is $2.5 \%$.

Additionally, the upstream flow was characterized $15 \mathrm{~cm}$ upstream from the wake generating bars using a combination of single- and triplewire anemometry to identify the characteristics of the flow and ensure approach flow uniformity. Profiles of the approach flow velocity and $T I$ are shown in Fig. 4. Examining this figure, note that while the approach flow shows a significant boundary layer, the approach flow between the leading edges of the turbine passage is uniform. The integral length scales of the approach flow, calculated using the auto-correlation technique (and verified by extrapolating the power spectra of the flow) are presented in Fig. 2.

To ensure that the flow through the passage correctly represents flow in a turbine passage, the pressure profile of wake-free flow was collected and compared to the design data for the blade. A profile of the measured pressure coefficient is shown in Fig. 5, along with the design data and the data reported for the wake-free flow of Qiu [8]. The wake-induced pressure profiles were not collected since unsteady pressure measurements could not be taken al the very low speed of this test.

\section{EXPERIMENTAL RESULTS}

In this section, the basic features of the unsteady flowfield are discussed. As mentioned previously, the introduction of wakes into the approach flow greatly disturbs the flow from that of the steady state case. The passing of wakes across the turbine blade suction surface introduces a number of significant flow features:

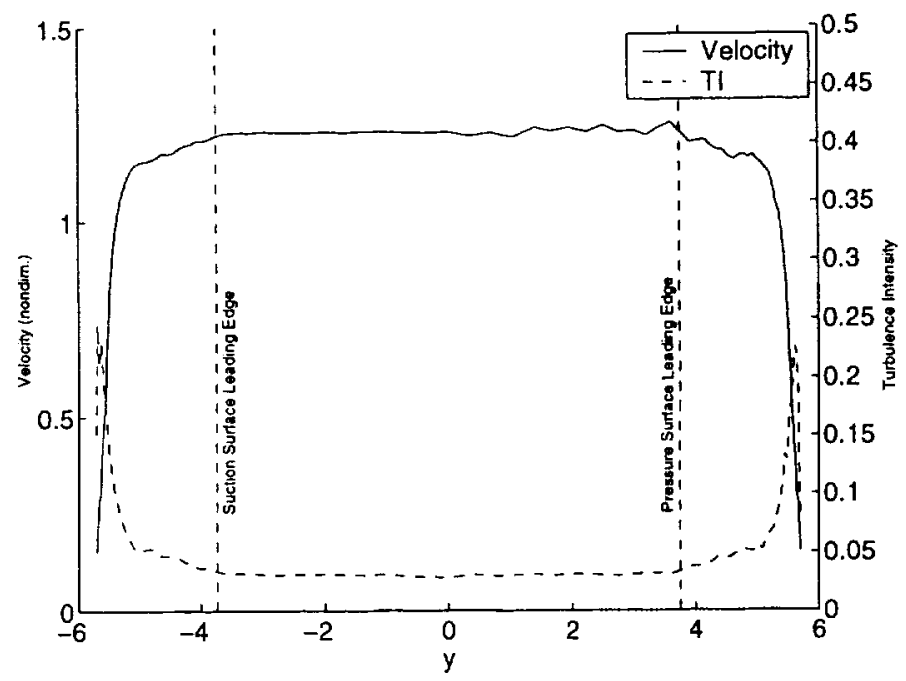

Figure 4. Approach flow velocity and $T I$ distributions, $15 \mathrm{~cm}$ upstream from the wake generating bars.

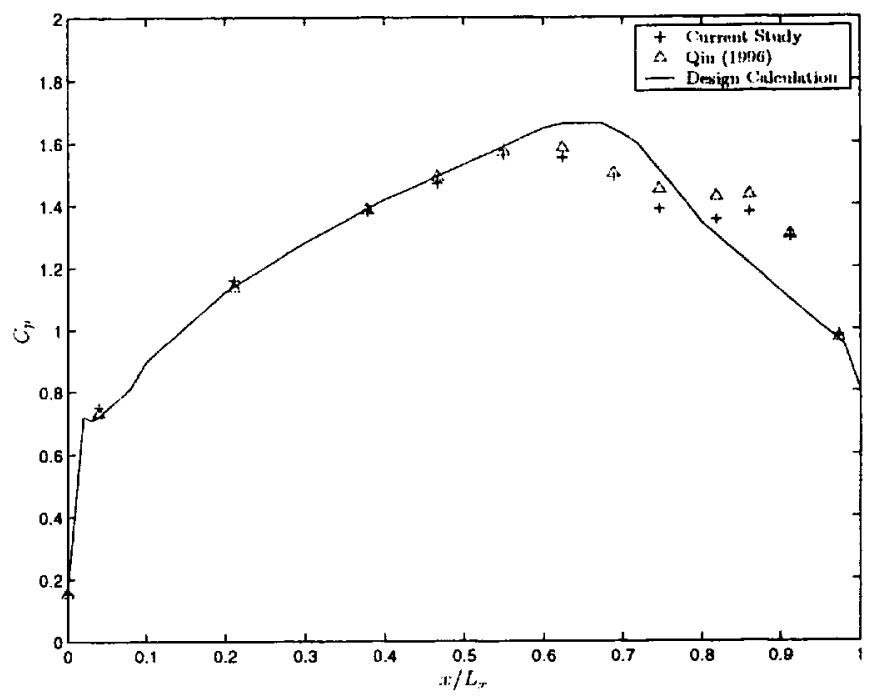

Figure 5. Pressure Coefficient Distribution for the Wake-Free Flow at $R e=50,000$ and $F S T I=2.5 \%$

1. The velocity deficits created by the wakes result in an oscillating free-stream velocity component, which adds temporal acceleration effects to the flow in addition to the spatial acceleration effects of the turbine passage geometry.

2. Similarly, this periodic oscillation in freestream velocity results in the turbine airfoil undergoing periodic oscillation in its angle of attack, thus the effective "origin" of boundary layer development at the leading edge moves as a function of time and the pressure distribution over the test surface changes accordingly.

3. The passing of the turbulent wakes creates wake "turbulence zones" which are convected through the passage, locally increasing lurbulence. When present over the suction surface, they cover a large fraction of that surface. 

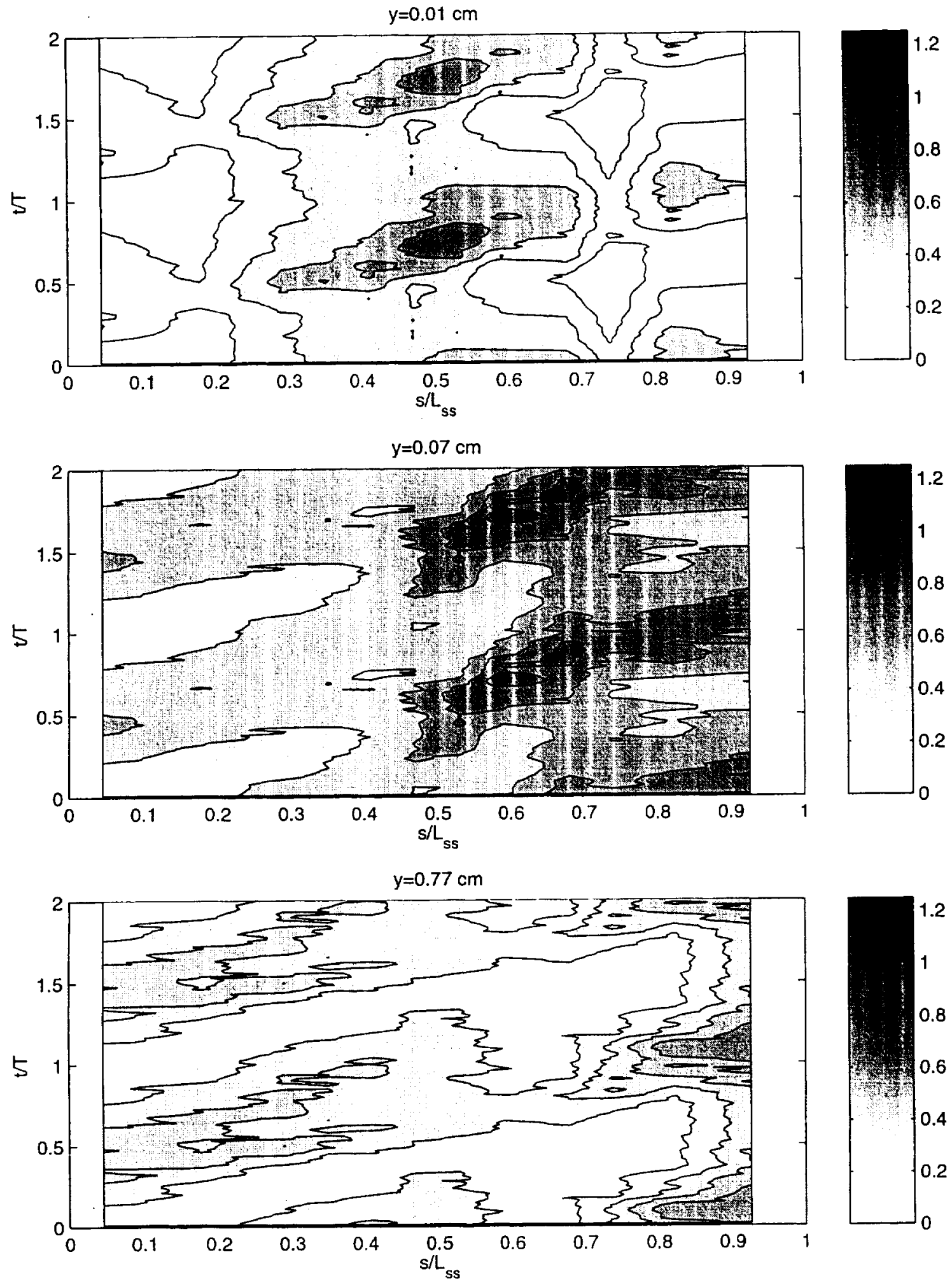

Figure 6. The rms velocity fluctuation $\widehat{u_{i m s}}(s, l)[\mathrm{m} / \mathrm{s}]$ as at function of suction surface length, $s / L_{x s}$, and time, $t / T$, at three different wall-normal distances. 
As an aid in understanding the nature of the wakes' effects on the turbine passage flow, plots of $\overline{u_{r m s}}(s, t)$ at various distances from the wall are presented (Fig. 6). Examining this figure, one sees that in the flow nearest to the freestream (the bottom plot, at $y=0.77 \mathrm{~cm}$ ), the wakes appear as diagonal bands of increased turbulence moving from the lower left to the upper right of the figure-as time passes ( $t$ increases), the wakes pass along the surface of the blade ( $s$ increases). Note that since the flow is a developing unsteady boundary layer, the boundary layer thickness varies in both $s$ and $t$ (see Figs. 7 and 10, for example) and the planes shown in Fig. 6 may, at different locations, indicate fow inside or external to the boundary layer.

When examining the flow in more detail, we can see some interesting effects induced by the passage of the wakes. Looking at the ensemble-average velocity distribution in the flow, as plotted in Fig. 7 for $s / L_{x i s}=47 \%$, we see evidence of a time lag between the freestream flow and the near-wall region flow. Examining Fig. 7, we see that the freestream flow accelerates over the period from $t / T=0.02$ to approximately $t / T=0.53$, and then begins to decelerate at $t / T=0.57$. However, examining the same figure, one observes that thickening of the boundary layer begins at $t / T=0.75$. Similarly, as the flow accelerates, starting at approximately $t / T=0.02$, the boundary layer thinning lags, beginning at approximately $t / T=0.3$.

The results at $s / L_{s i s}=47 \%$ (Figs. 7,8 and 9 ) allow identification of some interesting features of the fluctuation level distributions in the flow. At any point in the flow, the fluctuation level can result from a number of sources: (1) turbulence convected in from upstream, (2) turbulence generated due to attached boundary layer or separated shear layer transition and (3) turbulence convected in the wake's "turbulence zone." Examining the intermittency, Fig. 9, we clearly see the wake "turbulence zone," indicated by high values of $\bar{\gamma}(y, t)$ in the range $0.35<t / T<0.85$ at $y=1.6 \mathrm{~cm}$. However, in the near-wall region, the high intermittency values associated with the wake don't appear until $t / T \approx 0.70$, at $y=0.07 \mathrm{~cm}$. In the corresponding $\widetilde{u_{r m s}}(y, t)$ distribution (Fig. 8), it appears that a region of high velocity fluctuation occurs at approximately $y=0.07 \mathrm{~cm}$ between $0.30<t / T<0.75$, concurrent with the wake turbulence zone appearing overhead. This region of high $\mathrm{rms}$ velocity fluctuation starts to dissipate just as the turbulence intermittency in Fig. 9 begins to rise. Thus, in the portion of the flow which precedes separation, it appears that the wake turbulence zone in the free-stream flow induces a region of highly fluctuating flow (high $\widetilde{u_{r m w}}$ ). These fluctuations are apparently unstable and lead to breakdown to turbulence, creating the turbulence zones in the near-wall region in Fig. 9, from $0.70<t / T<0.85$. Then, as the wake turbulence zone passes and the flow begins to accelerate, the flow retums to laminar flow. A similar pattern of intermittencies and velocity fluctuations was seen at other preseparation locations $\left(s / L_{s, s}<50 \%\right)$.

This supports the theories presented by Johnson and Ercan [19, 20] and Mayle and Schulz [21], which were based on the hypothesis that the location of the onset point of transition is influenced primarily by pressure oscillations in the free-stream flow. However, it is important to note that there is a short time delay between when the flow is first affected by the wake turbulence zone and when the fow begins to undergo transition, an effect not captured by the models. This clearly shows the importance of including the dynamics of the transition process which are associated with the growth of instabilities and eventual generation of turbulence. This is the temporal equivalent to the spatial development process of bypass transition of a boundary layer under high free-stream turbulence. The level of the fluctuations induced by the free-stream turbulence (buffeting) increases in the downstream direction resulting in breakdown to turbulence. In natural transition these fluctuations will initially be linear instability modes that amplify and result in breakdown to turbulence.

In the present case there is unsteady separation. Separation was observed also in the wake-free, steady-state flow described in Simon et al. [9], starting at approximately $s / L_{x, s}=53 \%$. The phase-averaged velocity, $\tilde{u}(y, t)$, at $s / L_{x w}=68 \%$ is shown in Fig. 10 . For added clarity the individual velocity profiles are shown in Fig. 13. In general, the boundiry layer behavior is similar to that shown for $s / L_{s, s}=47 \%$, with the oscillating freestream velocity inducing a thinning and thickening of the near-wall viscous layer. However, unlike at the $s / L_{s, s}=47 \%$ position, there is strong evidence of separation in the flow at this location. Examining the figure, we initially see normal turbulent boundary layer profiles (from $0<t / T<30 \%$ ). However, they are unlike those at the $s / L_{s s}=47 \%$ position, in which the flow viscous region merely thickens and thins in response to the velocity oscillations of the free-stream flow. As the wake arrives at $s / L_{x x}=68 \%$, deceleration due to wake passage creates inflectional boundary layer profiles and the flow separates from the wall (starting at $t / T=46.7 \%$ ). The wake passes this station, then the flow accelerates and re-stabilizes until $t / T=86.7 \%$, when it reattaches. Similar results are seen at stations from $s / L_{s s} \approx 50 \%$ through $100 \%$. These observations are consistent with Lou and Hourmouziadis [22], who noted similar oscillations in the location and length of separation as a function of phase angle. For comparison purposes, phase-averaged velocity profiles, $\bar{u}(y, t)$, at $s / L_{s s}=47 \%$ are shown in Fig. 14. Examining this figure, we can see the oscillation of the freestream flow and the resulting thinning and thickening of the near-wall viscous layer, but no separation is observed.

Similarly, examining the $s-t$ plots of rms velocity fluctuation at $y=0.01 \mathrm{~cm}$ (the top plot in Fig. 6), we can observe also the onset of separation as a dramatic decrease in velocity fluctuation starting at $s / L_{x s} \approx 0.55$ and $t / T \approx 0.5$-as the flow separates from the wall, the high turbulence levels of the boundary layer are convected away from the wall, and the relatively low turbulence levels of the separation bubble are shown instead. When we examine the distribution further away from the wall, at $y=0.07 \mathrm{~cm}$ (the middle plot in Fig. 6), we see that the high rms fluctuations originally observed in the near-wall region have now appeared $\left(t / T \approx 0.58, s / L_{s s} \approx 0.55\right)$.

When we examine the distributions of $\bar{u}(y, t)$ (Fig. 10), $\widetilde{u_{r m} s}$ (Fig. 11) and $\bar{\gamma}$ (Fig. 12) at $s / L_{s i s}=68 \%$ we see the same correlation between the passing of the wake turbulence zone and near-wall transition that was seen at $s / L_{s s}=47 \%$ : it appears that the turbulent zones generated by the wakes induce some instabilities in the near-wall flow, which eventually trigger transition to turbulence. However, if we examine the protiles of $\widetilde{u_{r n m x}}$ and $\tilde{\gamma}$ carefully, we can see some differences from the pre-separational flow conditions at $s / L_{s s}=47 \%$. Since the flow has separated from the wall, a near-wall shear layer has developed (Fig. 13, at $t / T=63.3 \%$, for example).

As a result, the passing of the wake turbulence generates larger fluctuations in velocity than it did in the pre-separation flow (compare the size and magnitude of the high $\widetilde{u_{r m}}$ regions in the pre-separation flow in Fig. 8 to the post-separation flow in Fig. 11). 


\section{CONCLUDING REMARKS}

These results represent a detailed documentation of the eflects periodically passing wakes upon laminar-to-turbulent transition and flow separation in a low-pressure turbine passage. They represent the first detailed documentation of wall-normal, time-resolved velocity distributions inside such a periodically unsteady flow. Because all of the raw velocity measurements obtained in this study were retained, the results are available for processing using frequency-based techniques, such as wavelet analysis.

Additionally, the combination of detailed velocity profile data and the simplified turbine passage geometry of this study allow using these data for computer simulation. They should be valuable for continued development of turbine flow turbulence and transition models.

From these results, the following conclusions can be drawn:

1. The basic flow field of the wake-disturbed turbine passage flow is similar to that shown for the steady-state flow, with boundary layer growth, followed by separation of the flow. The primary effects of wakes are an overall increase in turbulence level due to the turbulence generated by the wakes, the imposition of temporal changes in freestream velocity which affect the instantaneous velocity profiles, the changing angle of attack of the approach flow and the movement of the location of the separation point due to these effects on mean flow and turbulence.

2. The rms velocity fluctuation and intermittency profiles seem to support the models of Johnson and Ercan [19] and Mayle and Schulz [21] for bypass transition, in which transition to turbulence in the bypass mode is due not to the direct introduction of turbulence to the boundary layer, but to the response of the near-wall boundary layer to pressure fluctuations in the free-stream flow.

\section{ACKNOWLEDGEMENTS}

This work is part of a study of transition in LP turbines sponsored by NASA Glenn Research Center under cooperative agreement \#NCC3652. Additional support in the form of graduate fellowships was provided by the Nation Science Foundation Fellowship Program and the University of Minnesota Doctoral Dissertation Fellowship Program.

\section{REFERENCES}

[1] Mayle, R. E., 199I, "The Role of Laminar-Turbulent Transition in Gas Turbine Engines," ASME J. of Turbomachinery, 113, pp. 509-537, The 1991 IGTI Scholar Lecture, also presented as ASME 91-GT-261.

[2] Simon, T. W. and Kaszeta, R. W., 2000, "Transition to Turbulence Under Low-Pressure Turbine Conditions," To be published, Proccedings of the International Symposium on Heat Transfer in Gas Turbine Systems, Cesme, Turkey, 13-18 August 2000, Annals of the New York Academy of Sciences.

[3] Jacobs, R. G. and Durbin. P. A., 2000, "Bypass Transition Phenomena Studied by Computer Simulation," Stanford University Report No. TF-77.

[4] Wolff, S.. Brunner, S., and Fottner, L., 2000, "The Use Of Hot-Wire Anemometry to Investigate Unsteady Wake-Induced Boundary Layer Development on a High-Lift LP Turbine Cascade." Presented at the $2000 \mathrm{In}$ ternational Gas Turbine and Aeroengine Congress and Exposition, Munich, Germany.

[5] Halstead, D. E., Wisler, D. C., Okiishi, T. H., Walker, G. J., Hodson, H. P., and Shin, H.-W., 1997, "Boundary Layer Development in Axial Compres- sors ind Turbines: Part 3 of 4: Low Pressure Turbines," ASME J. of Turbomachinery, 119. pp. 225-237, Also ASME 95-GT-463.

[6] Schobeiri, M. T. Read, K., and Luwalle. J., 1995, "Effect of Unsteady Wake Passing Frequency on Boundary Layer Transition," Presented at the 1995 International Gas Turbine and Aeroengine Congress and Exposition, Houston, Texas, ASME 95-GT-437.

[7] Qiu. S. and Simon. T. W., 1997, "An Experimental Investigation of Transition as Applied to Low Pressure Turbine Suction Surface Flows," Presented at the 1997 International Gas Turbine and Aeroengine Congress and Exposition, Orlando, Florida, ASME 97-GT-455.

[8] Qiu, S., 1996, An Experimental Study of Laminar to Turbulent Flow Transition With Temporal And Spatial Acceleration Effects, Ph.D. thesis, Universily of Minnesota, Department of Mechanical Engineering.

[9] Simon, T. W. Qiu, S., and Yuan, K., 2000. "Measurements in a Transitional Boundary Layer Under Low-Pressure Turbine Airfoil Conditions," NASA Contracior Report NASA/CR-2000-209957.

[10] Dorney, D. J., Flitan, H. C., Ashpis, D. E., and Solomon, W. J., 2000, "Effects of Blade Count on Boundary Layer Development in a Low-Pressure Tubine." AIAA 2000-0742.

[11] Wu, X. and Durbin, P. A., 2000, "Numerical Simulation of Heat Transfer in a Transitional Boundary Layer with Passing Wakes," ASME J. of Heal Transfer, 122, pp. 248-257.

[12] Suzen, Y. B. and Huang, P. G., 2000, "Modeling of Flow Transition Using an Intermittency Transport Equaton," J. of Fluids Eng., 123(2).

[13] Yuan, K., 1999, Simulation of Wakes: The Development of a Linear Cascalde Wake Generator, Master's thesis, University of Minnesota, Department of Mechanical Engineering.

[14] Wills, J. A. B., 1962, "The Correction of Hot-Wire Readings for Proximity to a Solid Boundary." J. of Fluid Mech., 12, pp. 388-396.

[15] Filco, R. E. and Gendrich, C. P., 1990, "The Turbulence Burst Detection Algorithm of Z. Zarić," in S. J. Kline and N. H. Afgan (eds.), "NearWall Turbulence 1988 Z. Zarić Meınorial Conference," pp. 911-931, Hemisphere.

[16] Walker, G. J. and Solomon, W. J., 1992, "Turbulent Intermittency Measurement on an Axial Compressor Blade," in M. R. Davis and G. J. Walker (eds.), "Eleventh Australasian Fluid Mechanics Conference," pp. 12771280. Hubart, Australia.

[17] Kaszeta. R. W., 2000, Experimental Investigation of Transition to Turbulence as Affected by Passing Wakes, Ph.D. thesis, University of Minnesota. Mechanical Engineering Department. Minneapolis, MN.

[18] Halstead, D. E., 1996, Boundary Layer Development in Multi-Stage Low Pressure Turbines, Ph.D. thesis, lowa State University, Ames, IA.

[19] Johnson, M. W. and Ercan, A. H., 1996, "A Boundary Layer Transition Model," Presented at the 1996 International Gas Turbine and Aeroengine Congress and Exposition, Birmingham, UK, ASME 96-GT-444.

[20] Johnson. M. W. and Ercan, A. H., 1999. "A Physical Model of Bypass Transition," Intl. J. of Heat and Fluid Flow, 20(2). pp. 95-104.

[21] Mayle, R. E. and Schulz, A., 1997. "The Path to Predicting Bypass Transition," A.SME J. of Turbomachinery, 119, pp. 405-411.

[22] Lou, W. and Hourmouziadis, J., 2000. "Separation Bubbled Under Steady and Periodic-Unsteady Main Flow Conditions," Presented at the 2000 International Gas Turbine and Aeroengine Congress and Exposition, Munich, Germany, ASME 2000-GT-270 


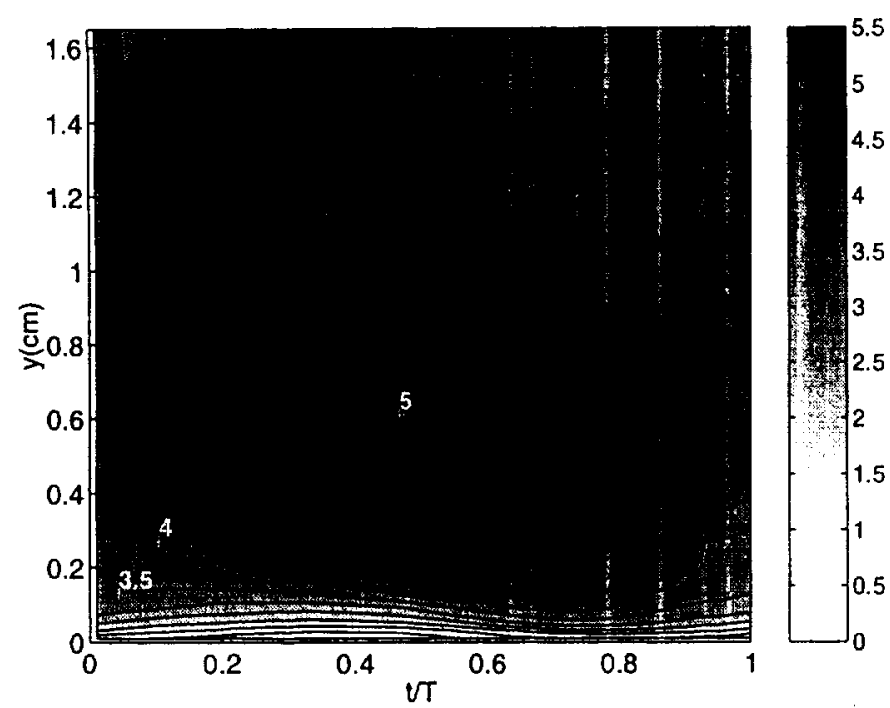

Figure 7. Phase average velocity $\tilde{u}(y, t)[\mathrm{m} / \mathrm{s}]$ at $s / L_{s s}=47 \%$

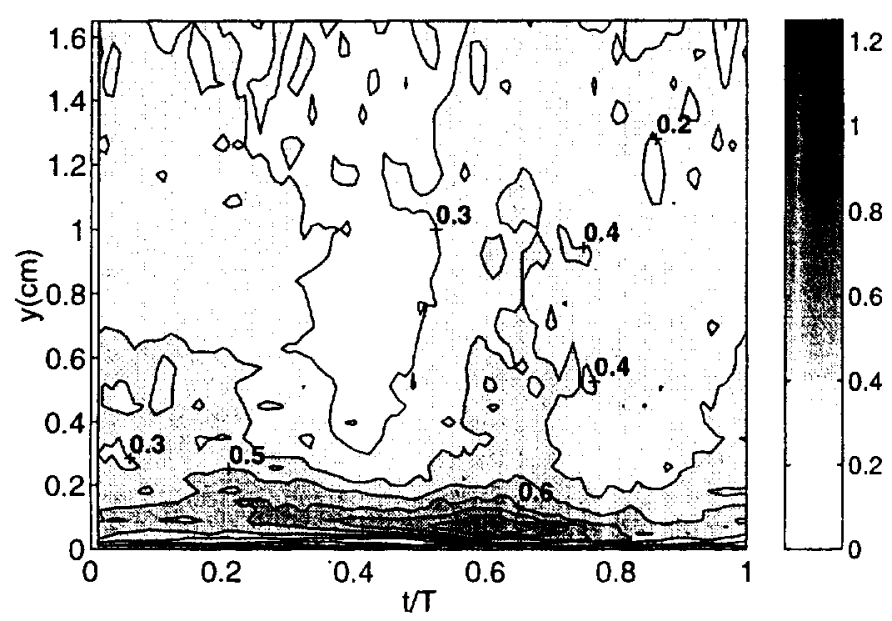

Figure 8. Phase average rms velocity $\widetilde{u_{r m s}}(y, t)[\mathrm{m} / \mathrm{s}]$ at $s / L_{x s}=47 \%$.

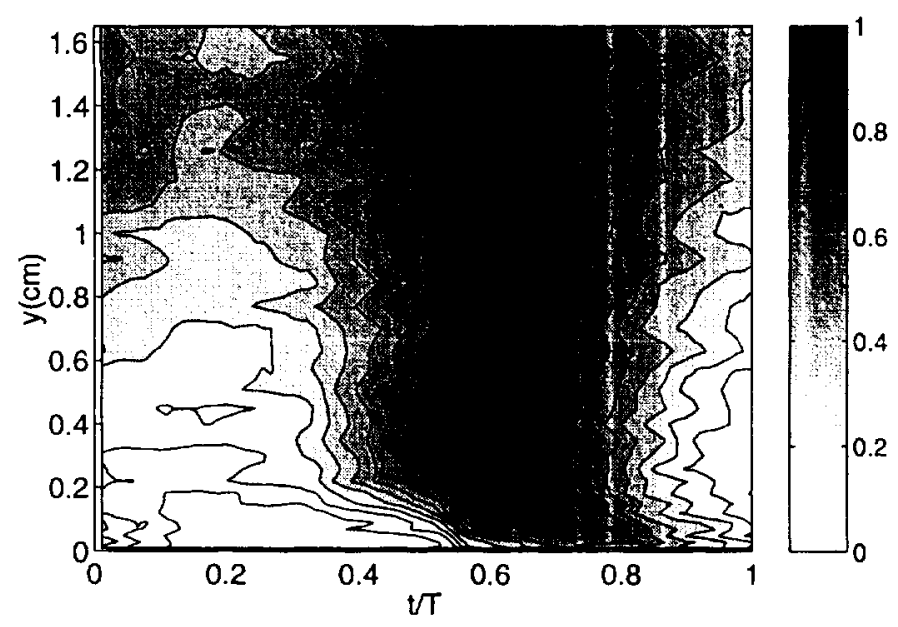

Figure 9. Phase average intermittency $\tilde{\gamma}(y, t)$ at $s / L_{x s}=47 \%$.

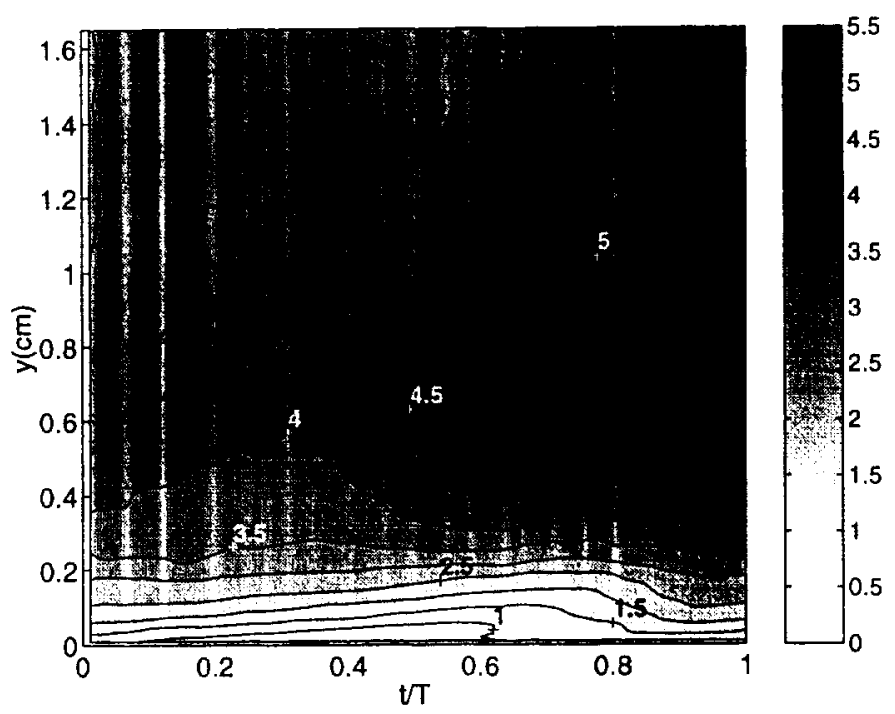

Figure 10. Phase average velocity $\bar{u}(y, t)[\mathrm{m} / \mathrm{s}]$ at $s / L_{r s}=68 \%$

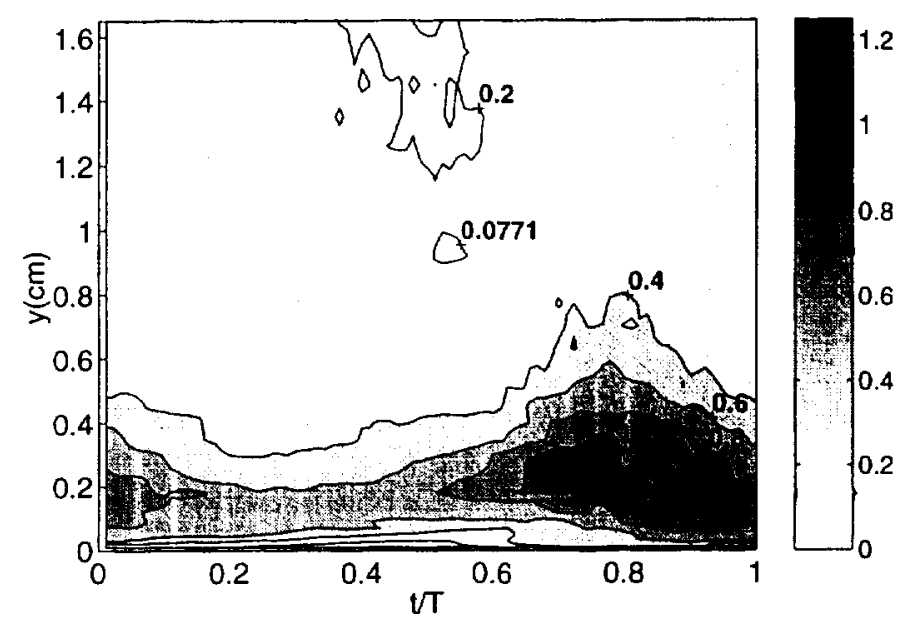

Figure 11. Phase average rms velocity $\widehat{u_{r m s}}(y, t)[\mathrm{m} / \mathrm{s}]$ at $s / L_{s s}=68 \%$.

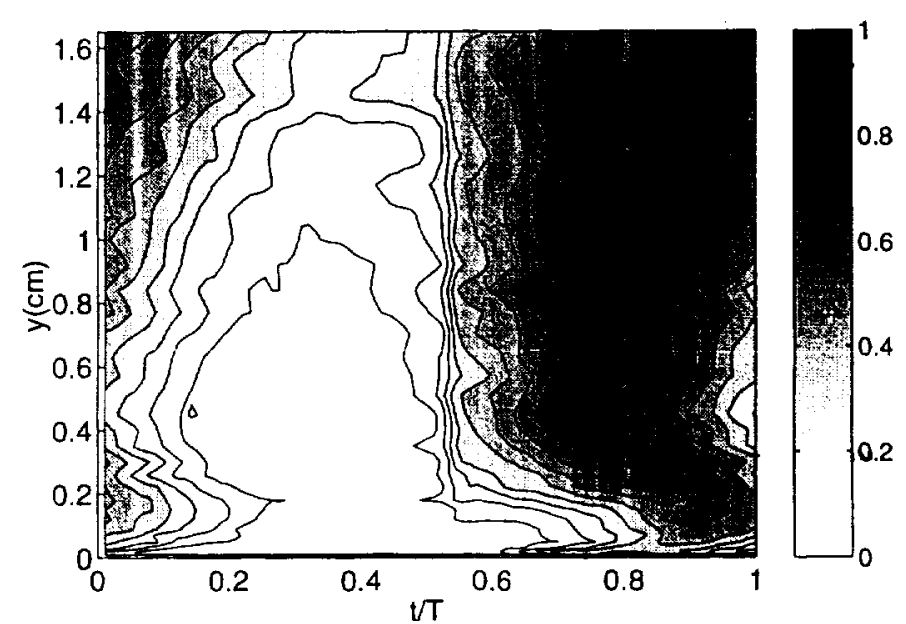

Figure 12. Phase average intermittency $\bar{\gamma}(y, t)$ at $s / L_{s s}=68 \%$. 


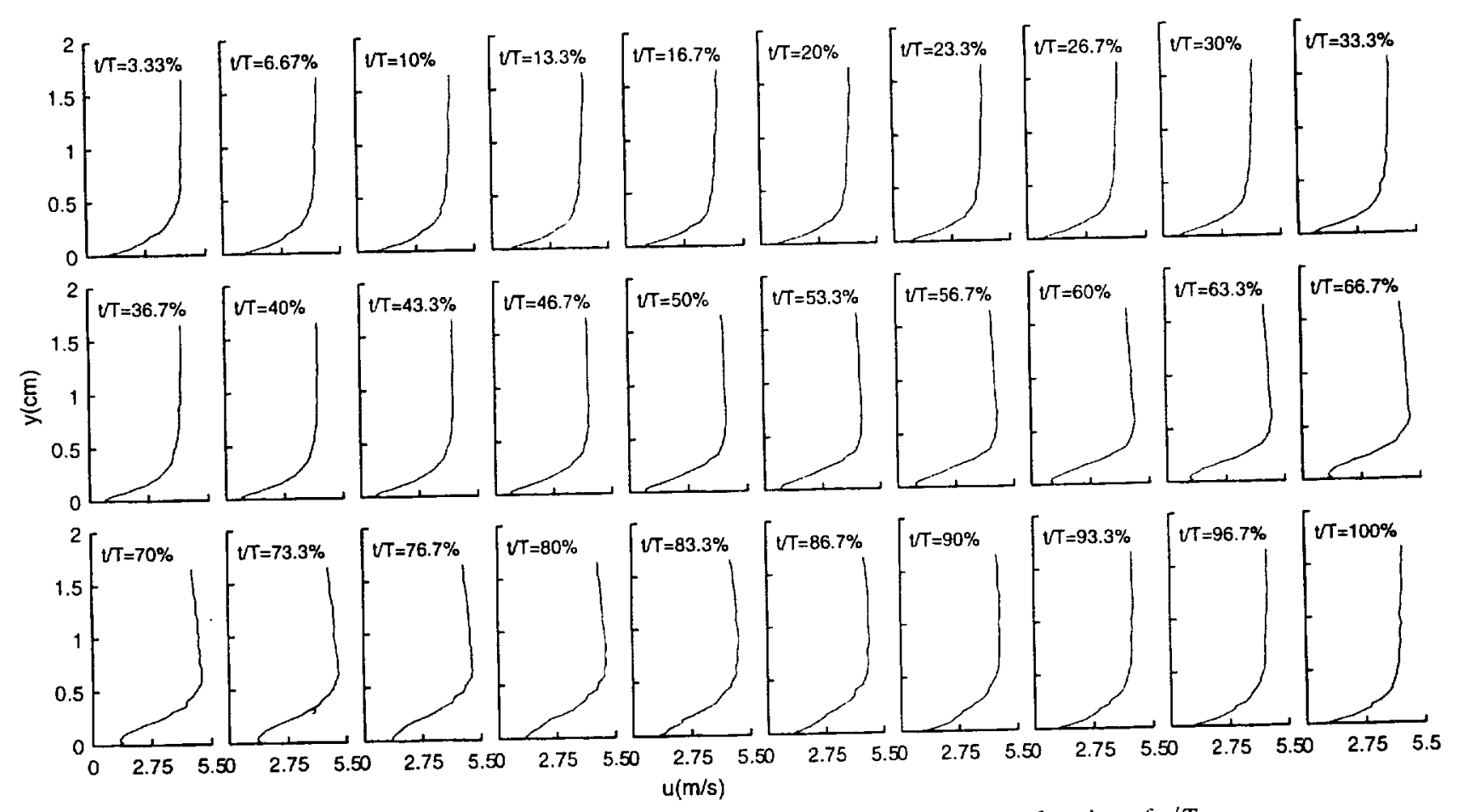

Figure 13. Phase average velocity $\tilde{u}(y, t)$ at $s / L_{s, s}=68 \%$, presented as a function of $t / T$.

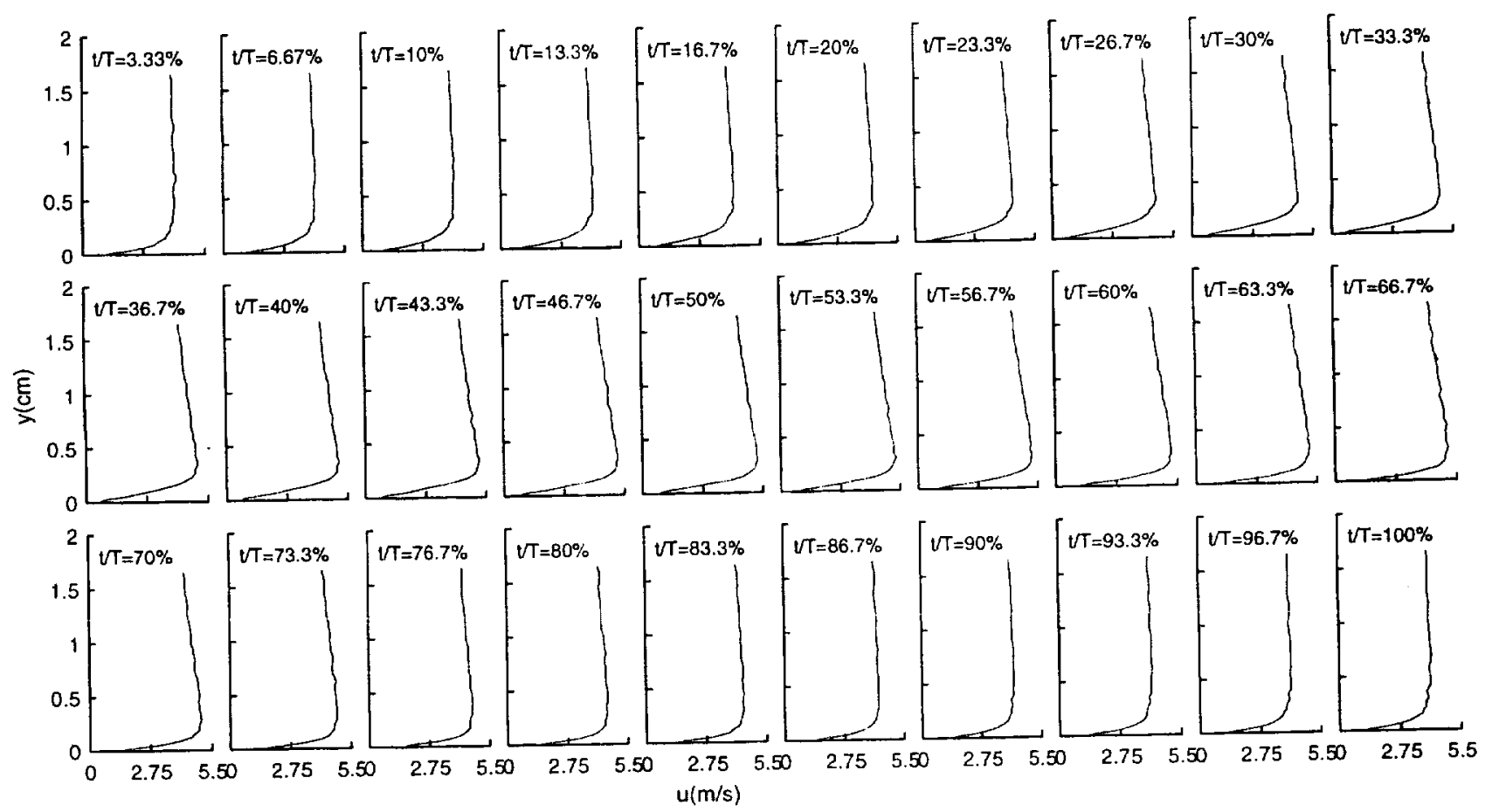

Figure 14. Phase average velocity $\tilde{u}(y, t)$ at $s / L_{s s}=47 \%$, presented as a function of $t / T$. 